\title{
Conflito de Interesses em Eventos de Educação Médica Continuada (EMC): o que Palestrantes e Ouvintes Consideram Importante que Seja Declarado? \\ Conflicts of Interest at Continuing Medical Education Events: What do Speakers and Listeners Believe must be Declared?
}

\section{PALAVRAS-CHAVE \\ - Ética Médica; \\ - Conflito de Interesses; \\ - Educação Médica Continuada; \\ - Educação Médica.}

\section{KEYWORDS}

- Medical Ethics;

- Conflicts of Interest;

- Continuing Medical Education;

- Medical Education.
Recebido em: 16/04/2015

Reencaminhado em: 18/01/2016

Aprovado em: 19/02/2016
José Domingos Neto João Alexandre Hool Bajerl ${ }^{I}$ Aluisio Serodio ${ }^{I}$

\begin{abstract}
RESUMO
Introdução: As companhias farmacêuticas representam a principal fonte de inovações terapêuticas na medicina, daí têm participação importante em eventos de educação médica continuada (EMC). Objetivos: Conhecer as concepções de médicos (palestrantes ou ouvintes) acerca do significado dos conflitos de interesses em eventos de EMC e que tipo de relação deveria ser declarado. Metodologia: Médicos que atuam numa universidade brasileira responderam a um questionário com perguntas abertas e fechadas. Os dados qualitativos foram analisados de acordo com uma análise de conteúdos, e os quantitativos submetidos a análise estatística apropriada. Resultados: Setenta e seis médicos responderam ao questionário; 55,3\% consideram o conflito de interesses como uma situação, enquanto 44,7\% o consideram um comportamento. Além do financiamento de pesquisa relacionada ao tema da palestra, mais da metade dos participantes apontou outros seis tipos de relacionamento indústria/palestrante cuja declaração é desejável. Cinquenta por cento dos palestrantes e $18 \%$ dos ouvintes acreditam estar bem preparados para lidar com as indústrias farmacêuticas. Considerações finais: Escolas médicas, Conselho Federal de Medicina e Associação Médica Brasileira deveriam trabalhar para aprimorar a compreensão dos médicos acerca do tema e criar regras claras sobre o que deveria ser declarado.
\end{abstract}

\section{ABSTRACT}

Introduction: Pharmaceutical companies are the main source of therapeutic innovations in medicine, thus playing an important role in continuing medical education (CME). Objectives: To study physicians'thoughts on conflicts of interests at CME events. Methodology: Physiciansworkingat a Brazilian public university responded to a questionnaire featuring open and closed questions, with qualitative data studied according to a content analysis and quantitative data subjected to a proper statistical analysis. Results: 76 physicians answered the questionnaire, with $55.3 \%$ considering conflicts of interests to constitute'situations' and $44.7 \%$ seeingthem as a form of behavior'. Besides financial support for research related to the presentations, the majority of participants pointed to six other kinds of industry/speaker relationship in which a declaration should be mandatory. Only 50\% of speakers and $18 \%$ of listeners feel prepared to deal with pharmaceutical companies' issues. Final considerations: Medical schools and medical representative entities should work toward improving physicians' understanding of this issue and creating objective rules on what must be declared.
REVISTA BRASILEIRA DE EDUCAÇÃO MÉDICA 


\section{A INFLUÊNCIA DA INDÚSTRIA FARMACÊUTICA EM EVENTOS DE EDUCAÇÃO MÉDICA}

Tradicionalmente, a medicina tem sido caracterizada como a ciência das verdades transitórias. As mudanças são ininterruptas, e, no campo da terapêutica, as companhias farmacêuticas representam a principal fonte de inovações, já que praticamente todas as drogas que transformaram a medicina desde a segunda metade do século XX foram desenvolvidas pela indústria ${ }^{1}$. Por isso, quem quer que se envolva com eventos de educação médica continuada (EMC) está praticamente fadado a se relacionar com a indústria farmacêutica.

Praticamente todas as instituições relacionadas à saúde têm seu funcionamento de alguma forma atrelado às companhias farmacêuticas. Universidades, sociedades de especialidades, instituições governamentais, associações de pacientes e revistas médicas estão se relacionando de maneira cada vez mais íntima com a indústria ${ }^{2}$. Além de provedoras das mais importantes inovações terapêuticas, as companhias farmacêuticas estão se tornando a principal fonte de financiamento dos congressos e periódicos médicos, e sua participação no orçamento das instituições de pesquisa é crescente. Segundo o $\mathrm{ACCME}^{3}$ - Accreditation Council for Continuing Medical Education, instituto que há 18 anos coleta e divulga dados sobre os eventos de EMC nos EUA -, a participação da indústria farmacêutica e de equipamentos no orçamento dos eventos de EMC nos EUA quadruplicou entre 1998 e 2006. Nesse mesmo período, escolas médicas e sociedades de especialidades - que usam a sobra de recursos dos eventos de EMC para custear outras atividades - aumentaram suas margens de lucro nesses eventos de $5,5 \%$ para 20,7\% (escolas médicas) e 46,3\% (sociedades de especialidades) ${ }^{3}$.

De 2008 em diante, entretanto, a parcela do orçamento de eventos de EMC financiada pela indústria de medicamentos e equipamentos começou a diminuir, tendo caído de 60,6\% em 2006 para $38 \%$ em $2014^{4}$. Ainda que mudanças na metodologia de coleta de dados empregada pela ACCME a partir de 2010 possam levar a uma superestimação desta queda, a tendência de diminuição vem se mantendo desde $2011^{4}$. Para Steinman et al..$^{5}$, esta tendência é fruto da desconfiança da sociedade estadunidense em torno do relacionamento entre médicos e indústria, que levou o governo a cogitar medidas legislativas restritivas. Os autores sugerem que regras claras e abrangentes em relação às declarações de conflitos de interesses podem colaborar com esta tendência.

Em termos absolutos, o poder da indústria farmacêutica pode ser atestado por alguns números. $\mathrm{O}$ movimento de vendas do mercado farmacêutico mundial saltou de US\$ 602 bilhões no ano de $2006^{6}$ para US\$ 1,06 trilhão de dólares em
20147. Levando em conta que, de acordo com a Organização Mundial de Saúde ${ }^{8}$, um terço da receita advinda destas vendas é gasto com o marketing dos medicamentos, atualmente cerca de US\$ 353 bilhões são investidos anualmente pelas companhias farmacêuticas na promoção de suas drogas em todo o mundo.

No Brasil, segundo a Associação da Indústria Farmacêutica de Pesquisa (Interfarma) ${ }^{9}$, o mercado de medicamentos movimentou $\mathrm{R} \$ 41,8$ bilhões em 2014. Se seguirmos a estimativa da OMS, a indústria farmacêutica investiria cerca de $\mathrm{R} \$ 13,8$ bilhões para divulgar seus produtos no Brasil. Levando em conta que o orçamento do Ministério da Saúde do Brasil em 2014 foi de R\$ 106 bilhões- e tomando como base a cotação do dólar em janeiro de 2014 -, a indústria farmacêutica investiu globalmente no marketing de seus produtos cerca de oito vezes o que o governo brasileiro gastou com saúde. Se considerarmos apenas a estimativa de investimento em marketing no Brasil, os "laboratórios" teriam investido cerca de 13\% do valor do orçamento do Ministério da Saúde.

Fazer uma estimativa da porção desses bilhões de fato destinada a eventos de EMC é muito difícil. Mas, uma vez que a publicidade direta ao consumidor de produtos de prescrição médica é proibida no Brasil, podemos inferir que boa parte desses recursos foi destinada à propaganda para os médicos e ao patrocínio de eventos de EMC. Uma rápida busca nos sites dos congressos brasileiros de algumas especialidades evidencia o peso da indústria farmacêutica no patrocínio desses eventos: em 2015, os congressos brasileiros de dermatologia, cardiologia e urologia tiveram, em média, 50 patrocinadores cada, sendo que 44 deles eram empresas farmacêuticas ou de equipamentos e materiais médicos.

Uma das estratégias de marketing empregadas pela indústria é influenciar os formadores de opinião da classe médica para divulgar seus produtos. Esta influência pode ocorrer de maneira direta (por meio da contratação como palestrante em simpósios satélites ou da orientação para fazer perguntas específicas em conferências e simpósios ${ }^{11}$ ) ou indireta (como doar recursos para reformas ou aquisição de equipamentos, pagar viagens para congressos, patrocinar eventos sociais ou educacionais, etc.). Até mesmo o patrocínio de ensaios clínicos, especialmente estudos de relevância científica discutível, pode ser visto como uma forma de cooptar formadores de opinião.

O fato é que a indústria de medicamentos lança mão de especialistas, professores e pesquisadores para conferir maior credibilidade aos seus produtos nos mais diversos eventos de educação médica continuada. É o que o diretor de uma empresa de relações públicas que presta serviços à indústria farmacêutica chama de third party technique ${ }^{11}$ : 
Não se trata de colocar palavras na boca de líderes de opinião. É basicamente utilizar uma outra fonte para apresentar os fatos sem que isso seja visto como algo manipulado pela companhia farmacêutica. (p. 1205)

Em nome da preservação da confiança pública na medicina, é fundamental definirmos que tipo de relacionamento com a indústria farmacêutica deveria ser declarado no início das palestras. Para isso, vale a pena esclarecer o que significa "conflito de interesses", o que, de fato, os médicos brasileiros consideram importante que seja declarado e a quem esta declaração deve ser dirigida.

Levando em conta que as escolas médicas, além de serem responsáveis pela formação da audiência dos eventos de EMC, fornecem grande parte dos palestrantes para estes eventos, procuramos conhecer entre os médicos que atuam numa grande universidade brasileira quais as suas concepções acerca do significado dos conflitos de interesses e que tipo de relação com a indústria farmacêutica seria de declaração obrigatória antes do início de uma palestra.

\section{OBJETIVOS}

\section{Objetivo geral}

- Conhecer as concepções de médicos que atuam numa universidade pública brasileira e participam de eventos de EMC acerca do significado dos conflitos de interesses.

\section{Objetivos específicos}

- Identificar, na opinião de médicos que atuam nessa universidade, que tipo de relação com a indústria farmacêutica deveria ser declarado por um palestrante num evento de EMC;

- Determinar, segundo a visão destes profissionais, a quem deveria ser dirigida uma declaração de conflito de interesses (organização do evento? plateia?);

- Conhecer o grau de satisfação de palestrantes e ouvintes sobre seu preparo para lidar com as investidas de marketing da indústria farmacêutica em eventos de EMC;

- Identificar possíveis diferenças de concepção entre palestrantes e ouvintes.

\section{METODOLOGIA}

O local de coleta de dados foi a escola médica de uma grande universidade pública brasileira. Os critérios de inclusão para os sujeitos da pesquisa foi que fossem médicos que tra- balhassem nessa instituição e que tivessem participado de eventos de EMC, seja na qualidade de palestrante, seja na de ouvinte.

Esta pesquisa é de caráter exploratório, do tipo descritivo-analítica. O instrumento para coleta dos dados foi um questionário composto por duas perguntas abertas e oito fechadas.

Os dados quantitativos são apresentados de acordo com suas frequências relativas, e o teste do Qui-Quadrado com nível de significância de 0,05 foi empregado para avaliar diferenças entre palestrantes e ouvintes quanto a quais relações palestrante/indústria deveriam ser declaradas.

Os dados qualitativos foram estudados utilizando-se uma análise por categorização, considerando-se as concentrações temáticas das respostas.

Foi realizado um pré-teste do questionário com os professores da disciplina de Bioética do curso médico dessa universidade.

Este projeto foi realizado com estímulo do Conselho Regional de Medicina de São Paulo (Cremesp) no sentido de introduzir estudantes de Medicina na área de pesquisa em Ética Médica e Bioética ${ }^{12}$. Por isso, a estratégia para aplicação dos questionários foi a seguinte: após pedirem autorização às chefias de disciplinas e departamentos pelos quais estavam passando no internato do quinto ano médico, dois dos autores apresentaram sucintamente o projeto nas reuniões clínicas desses setores e entregaram os questionários aos médicos que desejavam participar da pesquisa. Os questionários respondidos foram recolhidos nas secretarias dos respectivos departamentos e disciplinas, ou pessoalmente por esses dois autores, à ocasião ainda estudantes.

Não era objetivo deste estudo encontrar diferenças entre os departamentos e disciplinas que participaram da pesquisa. Assim, neste artigo, a identificação desses setores foi mantida em sigilo pelos pesquisadores. Quando sugeriu esta estratégia para a aplicação dos questionários, o orientador não tinha conhecimento do rodízio dos estudantes no internato do quinto ano. Por isso, pode-se dizer que a escolha desses setores para participar da pesquisa foi feita ao acaso.

A pesquisa foi previamente autorizada pelo CEP da instituição. Para participar do estudo, todos os sujeitos de pesquisa assinaram um Termo de Consentimento Livre e Esclarecido.

\section{CARACTERIZAÇÃO DA POPULAÇÃO ESTUDADA}

Cento e oito questionários foram entregues e 76 respondidos (índice de devolução de 70\%).

Destes 76 médicos, 28 (37\%) eram contratados ou voluntários, $22(29 \%)$ residentes, 16 (21\%) pós-graduandos e 10 (13\%) docentes (Gráfico 1) 
Quanto à participação em eventos de educação médica continuada, 20 dos participantes $(26,3 \%)$ se caracterizaram como palestrantes e 56 (73,7\%) como ouvintes (Gráfico 2).

\section{GrÁFICO 1}

Caracterização da amostra estudada

especificando vínculo do médico participante

da pesquisa com a instituição estudada

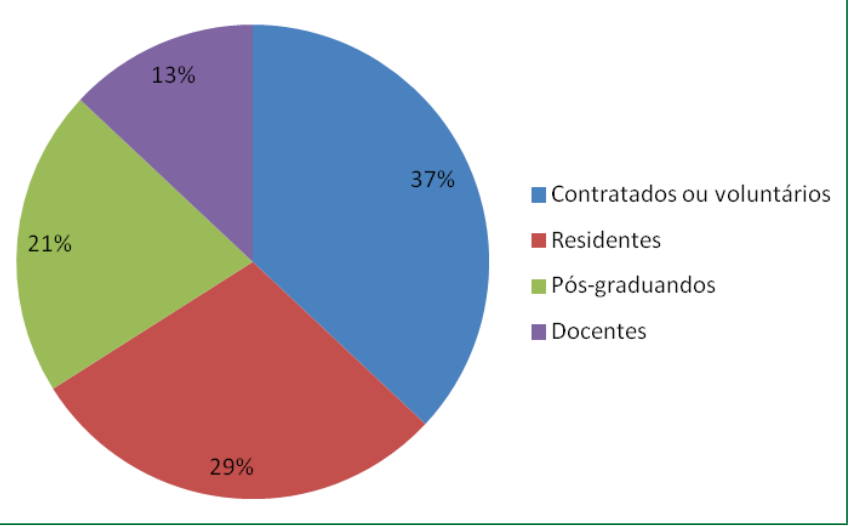

GrÁfico 2

Caracterização da amostra especificando a população estudada entre ouvintes e palestrantes

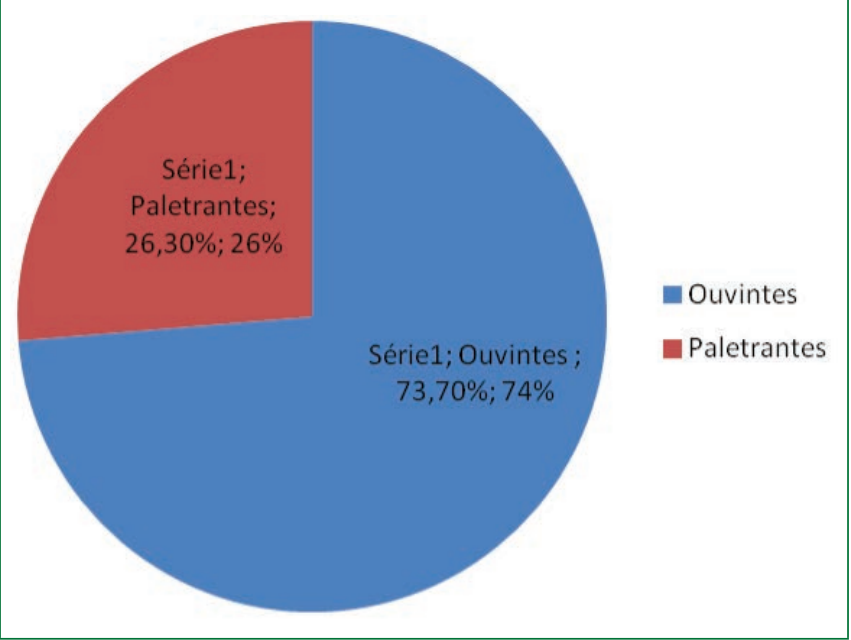

\section{RESULTADOS E DISCUSSÃO}

Questões fechadas

\section{- O que deveria ser declarado no início de uma palestra?}

Para a quase totalidade dos participantes (97,3\%), o palestrante deveria declarar se estivesse recebendo um financia- mento de pesquisa de medicamento relacionado ao assunto da palestra. Para mais da metade dos participantes, outros seis tipos de relacionamento entre palestrante e indústria deveriam ser declarados: (1) honorários para participação em simpósios ou conferências no mesmo evento de educação médica continuada $(63,1 \%)$; (2) propriedade de ações de companhia farmacêutica (57,8\%); (3) suporte para participação em eventos científicos (p.ex.: pagamento de passagens, estadia ou inscrição em congressos) (56,5\%); (4) doação de recursos para melhorias no serviço ao qual pertence o palestrante (56,5\%); (5) emprego $(56,5 \%) ;(6)$ consultoria remunerada $(56,5 \%)$

Ser acionista, diretor, consultor ou empregado de uma companhia farmacêutica caracteriza uma situação óbvia de conflito cuja declaração à audiência deveria ser obrigatória. Também parece ser o caso do recebimento de honorários para participar de simpósios satélites ou eventos patrocinados pela indústria: por gerar situações de conflito de interesses, este tipo de relação deveria ser do conhecimento dos ouvintes.

Já a relação indústria-pesquisador merece uma reflexão mais cuidadosa. Participar de projetos de pesquisa ligados às companhias farmacêuticas é uma condição não só inevitável como até desejável para a maior parte dos palestrantes. Entretanto, na realidade brasileira, ser o investigador principal de um projeto patrocinado pela indústria farmacêutica pode significar, além de prestígio acadêmico, o manuseio de verbas que podem corresponder a vários meses de salário de um professor universitário. Tanto o desejo de prestígio como a compensação financeira são interesses legítimos de um professor / pesquisador, mas criam situações de conflito que deveriam tornar compulsória uma declaração dirigida à plateia.

Quanto ao pagamento de passagens, estadias e inscrições em congressos, é difícil encontrar uma resposta categórica. Tais incentivos - ainda que envolvam valores relativamente pequenos - podem, até inconscientemente, influenciar o conteúdo das palestras; portanto, de acordo com a maior parte dos pesquisados, deveriam ser declarados. É importante enfatizar que, diferentemente da participação em projetos de pesquisa, um palestrante pode perfeitamente recusar esses incentivos sem grandes prejuízos para sua atividade profissional. Mas, se decide aceitá-los, deveria declará-los.

Decidimos submeter as respostas dadas a esta questão a uma análise estatística a fim de encontrar possíveis diferenças entre palestrantes e ouvintes. Utilizamos o teste do Qui-Quadrado com nível de significância de $0,05 \%$. Os resultados estão descritos na Tabela 1 .

É interessante notar que, contrariamente a uma hipótese prévia dos pesquisadores, os palestrantes parecem mais exigentes que os ouvintes quanto aos tipos de relacionamento palestrante-indústria que deveriam ser declarados. Uma explica- 
ção para este achado é que os palestrantes conheceriam muito melhor esta problemática, enquanto os ouvintes estariam despreparados em relação ao assunto. Uma evidência para este argumento pode ser encontrada na alternativa "emprego". Embora pareça claro que tal relação mereça uma declaração, apenas $46,4 \%$ dos ouvintes pensam assim, enquanto $85 \%$ dos palestrantes enxergam o óbvio $(p=0,002)$.

\section{TABELA 1}

Diferença estatística entre palestrantes e ouvintes para a questão: "Dentre os relacionamentos entre palestrantes e indústria farmacêutica descritos abaixo, assinale aqueles que deveriam, na sua opinião, ser declarados no início de uma palestra" (Teste do Qui-Quadrado, p < 0,05)

\begin{tabular}{|c|c|c|c|c|c|}
\hline \multirow{2}{*}{$\begin{array}{l}\text { O que deve ser declarado no } \\
\text { início de uma palestra? }\end{array}$} & \multicolumn{2}{|c|}{ Palestrantes } & \multicolumn{2}{|c|}{ Ouvintes } & \multirow[b]{2}{*}{$\mathbf{p}$} \\
\hline & $\mathbf{N}$ & $\%$ & $\mathbf{N}$ & $\%$ & \\
\hline $\begin{array}{l}\text { Financiamento de pesquisa } \\
\text { relacionado à palestra }\end{array}$ & 17 & 85 & 56 & 100 & 0,016 \\
\hline $\begin{array}{l}\text { Financiamento de pesquisa } \\
\text { não relacionado à palestra }\end{array}$ & 6 & 30 & 15 & 26,8 & 0,217 \\
\hline $\begin{array}{l}\text { Suporte para participação de } \\
\text { eventos (passagens, estadias, } \\
\text { etc.) }\end{array}$ & 12 & 60 & 31 & 55,4 & 0,195 \\
\hline $\begin{array}{l}\text { Honorário para atividades } \\
\text { num mesmo evento }\end{array}$ & 16 & 80 & 32 & 57,1 & 0,042 \\
\hline $\begin{array}{l}\text { Honorário para atividades } \\
\text { num evento diferente }\end{array}$ & 14 & 70 & 19 & 33,9 & 0,005 \\
\hline $\begin{array}{l}\text { Ajuda para realizar eventos } \\
\text { sociais ou científicos }\end{array}$ & 11 & 55 & 26 & 46,4 & 0,166 \\
\hline $\begin{array}{l}\text { Doações de recursos para } \\
\text { serviço ao qual pertence o } \\
\text { palestrante }\end{array}$ & 12 & 60 & 31 & 55,4 & 0,195 \\
\hline Consultoria remunerada & 16 & 80 & 27 & 48,2 & 0,010 \\
\hline Emprego & 17 & 85 & 26 & 46,4 & 0,002 \\
\hline $\begin{array}{l}\text { Propriedade de ações de } \\
\text { companhia farmacêutica }\end{array}$ & 14 & 70 & 30 & 53,6 & 0,096 \\
\hline Outros & 0 & 0 & 5 & 8,9 & 0,207 \\
\hline
\end{tabular}

- A quem dirigir a declaração de conflito de interesses? A grande maioria dos pesquisados $(73,7 \%)$ considera que a declaração deve ser feita à plateia, enquanto $46 \%$ pensam que deve ser feita à organização do evento.

Cremos ser importante que ambas, organização e audiência, sejam informadas quanto aos potenciais conflitos. A experiência da comissão científica de um congresso é importante para evitar distorções que ponham em xeque a credibilidade do evento. Entretanto, os próprios membros dessas comissões podem se encontrar numa situação de conflito de interesses menos de natureza financeira e mais ao redor da amizade, parentesco ou prestígio.
Situações que tenham escapado da atenção do palestrante e da comissão organizadora podem ainda ser detectadas pelos ouvintes, destinatários finais da mensagem (educativa e/ou de marketing). $\mathrm{O}$ respeito à audiência exige que lhe sejam fornecidas todas as informações para avaliar uma apresentação. Por isso, uma declaração dirigida à plateia parece indispensável.

A maior vantagem da declaração de conflito dirigida à plateia é fornecer àqueles que serão diretamente influenciados pela apresentação informações importantes para que decidam acerca da qualidade da palestra. O principal problema com estas declarações é que a audiência pode ter dificuldade para interpretá-las.

\section{- Valores envolvidos deveriam ser declarados?}

Quando a declaração envolve discriminação dos valores envolvidos, os resultados mostram que a maior parte dos participantes (60,5\%) não é favorável à divulgação, ainda que $30,3 \%$ acreditem que os valores devam ser divulgados para a plateia e 9,2\% apenas para a organização do evento.

- Os médicos sentem-se preparados para lidar com as indústrias farmacêuticas?

Esta pergunta teve como objetivo analisar o preparo dos profissionais médicos em se relacionar com o envolvimento das indústrias nos eventos de EMC. De acordo com os dados apresentados, 26,1\% acreditam estar bem preparados, 50,8\% afirmaram estar razoavelmente preparados, enquanto $23,1 \%$ se consideraram despreparados.

Vale salientar que, ao dividirmos os grupos em "palestrantes" e "ouvintes", observamos que o público-alvo das palestras se considera menos preparado que os palestrantes (Gráfico 3).

\section{GrÁfico 3}

Frequências relativas das respostas à questão: "Como você caracterizaria seu preparo para lidar com as estratégias de marketing da indústria farmacêutica em eventos de educação médica continuada?"

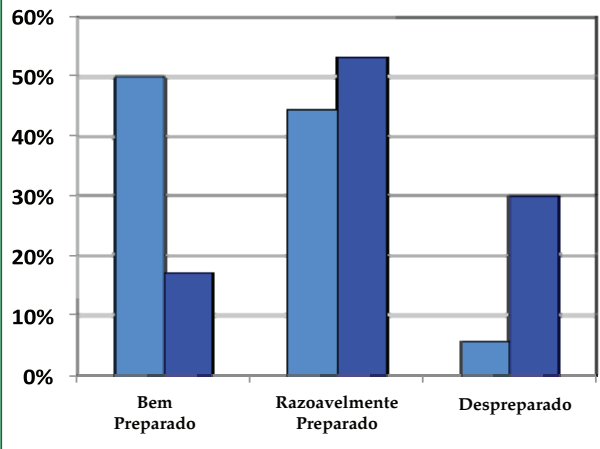




\section{- Como esse preparo foi adquirido?}

O estudo apontou que 58,6\% adquiriram seu preparo com a experiência profissional, enquanto $27,1 \%$ na pós-graduação e 14,3\% durante a graduação.

Este dado aponta uma grande incompetência do aparelho formador na discussão deste tema, uma vez que a maioria dos pesquisados acaba por desenvolver alguma competência para lidar com o assunto durante sua atuação profissional, sem qualquer tipo de planejamento educacional.

\section{Questões abertas}

- "O que você entende por conflitos de interesse"?

As categorias da análise para esta questão, elaboradas $a$ priori de acordo com a literatura especializada, foram: "situação" e "comportamento".

Definimos a categoria "situação" de acordo com Thompson ${ }^{13}$ : o conflito de interesses corresponde a uma série de situações nas quais o julgamento do profissional, no que diz respeito aos interesses primários daquela atividade, tende a ser indevidamente influenciado por um interesse secundário.

Caracterizamos como "comportamento" respostas que identificavam um conflito de interesses quando a apresentação já teria sido influenciada indevidamente por um interesse secundário.

Entre os participantes, 55,3\% caracterizaram conflito de interesses como situação, enquanto $44,7 \%$ das respostas corresponderam à categoria "comportamento".

\section{Conflito de interesses como situação}

Quando você é financiado por empresas, órgãos públicos e instituições que podem influenciar o tipo de informação que você está transmitindo às pessoas. (residente, ouvinte)

Esta concepção é a mesma que os autores consideram a mais adequada e está de acordo com grande parte da literatura especializada: um agente que possa se beneficiar financeiramente de alguma distorção de seu trabalho está numa situação de conflito, independentemente de ter ou não deixado um interesse secundário prevalecer ${ }^{14}$. Entendemos, assim, que não há nada inerentemente antiético no fato de alguém se encontrar numa situação de conflito.

\section{Conflito de interesses como comportamento}

Há conflito de interesses quando o médico, por exemplo, não é independente em relação ao assunto que está discutindo, ou seja, por algum motivo ele atende à solicitação de alguma empresa ou setor, sendo tendencioso a favor dela, podendo ainda, devido a seu renome, influenciar pessoas com sua opinião. (pós-graduando, ouvinte)
Entendemos que esta concepção, adotada por quase a metade dos participantes, leva a um problema insolúvel: se considerarmos os conflitos de interesses como um comportamento, nenhum palestrante iria declará-los, uma vez que isto significaria admitir uma conduta eticamente reprovável. Há uma reação exacerbada de alguns colegas que enxergam na ênfase dada aos potenciais conflitos de interesses uma afronta à sua integridade profissional. Por isso, é fundamental reforçar a ideia de que o conflito de interesses é uma situação e não um comportamento ${ }^{14}$; e o primeiro passo para lidarmos com esta condição é reconhecer sua existência ${ }^{15}$.

- "Você considera que uma declaração de conflitos de interesses poderia aumentar a credibilidade de um evento de educação médica continuada? Por quê?"

Para esta questão, as categorias foram estabelecidas após a leitura cuidadosa das respostas de forma independente pelos três pesquisadores. Quando houve discordância, prevaleceu a opinião do orientador, por ter maior experiência com a abordagem qualitativa.

Dos entrevistados, 80,3\% responderam "sim", considerando que a declaração de conflito de interesses aumentaria a credibilidade dos eventos de EMC. Por outro lado, 19,7\% responderam "não", acreditando que a declaração de conflito de interesses não aumentaria a credibilidade dos eventos de EMC.

\section{Categorias da resposta "sim"}

Transparência do evento/honestidade do palestrante

\begin{abstract}
Acho que a declaração pode ser feita, pois demonstra a transparência do evento e a honestidade do palestrante; mas com o cuidado de não se vincular a ideia de que todo trabalho deva ser "indagado"(suspeito) por haver vínculo. (pós-graduando, ouvinte)
\end{abstract}

Esta categoria mostra-se bastante compatível com a concepção de "situação", principalmente porque oferece a possibilidade de o palestrante ser ou não influenciado por interesses secundários. Ao mesmo tempo, compartilha o entendimento de que não é eticamente condenável estar numa situação de conflito de interesses.

\section{Subsídios para melhorar a avaliação (visão crítica) da audiência}

Estamos em constante mudança e aprendizado, e expor conflitos nos torna mais pensantes, atuantes e quem sabe seja estimulante. (médico contratado ou voluntário, ouvinte)

Nesta categoria, explicita-se a noção de que a exposição dos conflitos de interesses colabora para aprimorar a visão crítica 
dos ouvintes acerca da palestra. Oferece subsídios para que o ouvinte possa decidir se a informação é ou não influenciada por interesses secundários. Nesse sentido, a maior vantagem da declaração de conflito dirigida à plateia é fornecer àqueles que serão diretamente influenciados pela apresentação informações importantes para que decidam acerca da qualidade da palestra.

\section{Uniformidade das regras}

Sim, desde que feita de forma uniforme. (docente, palestrante)

Especialmente para os palestrantes, há um anseio por regras claras acerca da declaração de conflitos de interesses. Nesse sentido, para que sejam observadas com rigor, as políticas de regulamentação de conflitos de interesses devem ser explícitas ${ }^{1}$. Infelizmente, as diretrizes disponíveis em nosso meio são muito vagas, causando dúvidas aos palestrantes e inquietações na plateia. Os próprios profissionais que trabalham em parceria com a indústria parecem pedir regras mais claras sobre como proceder ${ }^{16}$. Podemos apontar três instâncias com legitimidade para regulamentar as situações de conflito: o Conselho Federal de Medicina (CFM), as sociedades de especialidades e o poder público.

Por intermédio da Resolução 1.595/2000, posteriormente complementada pela Resolução 1.974/2011, o CFM ${ }^{17}$ determina que:

os médicos, ao proferir palestras ou escrever artigos divulgando ou promovendo produtos farmacêuticos ou equipamentos para uso na medicina, declarem os agentes financeiros que patrocinam suas pesquisas e/ou apresentações [...].

Ademais, o CFM, a Associação Médica Brasileira (AMB), a Sociedade Brasileira de Cardiologia (SBC) e a Interfarma, em defesa das boas práticas no relacionamento entre classe médica e a indústria farmacêutica feita em 2012, propõem que:

as empresas associadas à Interfarma diligenciarão para que todo o público de interesse seja informado sobre potenciais conflitos éticos surgidos em razão de interesses financeiros ou econômicos que porventura existam entre a indústria farmacêutica e os profissionais médicos. ${ }^{18}$

Mencionar uma medicação durante a palestra é uma forma de divulgação, ainda que a intenção do palestrante não seja promover o medicamento. Por isso, de acordo com o espírito da resolução, caso o palestrante participe de projetos de pesquisa que envolvam aquela medicação ou algum dos seus concorrentes, a declaração de conflito é compulsória. E se o palestrante estiver participando de projetos financiados pela mesma companhia farmacêutica referentes a outras drogas, deveria declarar esta participação? E se a companhia que produz aquela medicação tiver custeado a participação do palestrante num congresso internacional ou financiado a instalação de um laboratório no centro de pesquisas ao qual o palestrante está associado, isto deveria ser declarado? Embora tais situações configurem potenciais conflitos de interesses, não existe qualquer alusão às mesmas nas resoluções e no posicionamento supracitados. Por isso, pode-se afirmar que estes documentos se mostram muito vagos, gerando pouco esclarecimento na determinação do que deve ser divulgado em eventos de EMC.

Categorias para a resposta "não"

Receio de perder a credibilidade

Via de regra, quando ficamos sabendo dessas relações, nossa credibilidade no profissional tende a cair... (médico contratado ou voluntário, ouvinte)

Esta categoria é compatível com a concepção "comportamento". Com isso, o participante demonstra compartilhar da noção de que declarar um conflito é admitir conduta eticamente reprovável, e, portanto, a declaração leva à perda da credibilidade do palestrante.

\section{Não há como averiguar a veracidade das informações}

Na maioria das vezes a declaração não é feita de forma fidedigna, pois poderia prejudicar o palestrante. Além disso, não tem como ser feita fiscalização para adequada veracidade das informações prestadas.(pós-graduando, ouvinte)

Se deixarmos exclusivamente a critério do próprio palestrante decidir sobre a existência do conflito, é provável que muitas situações mais sutis passem despercebidas. Poderiam os palestrantes negar categoricamente obrigações subconscientes de reciprocidade que existem quando benefícios são oferecidos e aceitos ${ }^{19}$ ? Seguramente, confiar na boa-fé do palestrante é algo indispensável, mas insuficiente para garantir a credibilidade de um simpósio ou conferência. Sempre haverá a possibilidade de declarações fraudulentas. Talvez pudesse caber à organização do evento desenvolver meios para dificultar tais declarações.

Credibilidade deveria depender do conteúdo da apresentação, e não do palestrante

A credibilidade depende do conteúdo da aula, baseada em evidências.(pós-graduando, ouvinte) 
O foco desta categoria é a necessidade de aprimorar o conhecimento dos ouvintes acerca da epistemologia da ciência, ou seja, a necessidade de médicos não serem "ingênuos científicos",mas, sim, capazes de avaliar o conteúdo da palestra, independentemente das credenciais do palestrante.

\section{As informações são relativas e sujeitas a interpretações}

Não, pois esta informação é muito relativa, podendo ter diferentes interpretações. (docente, palestrante)

De fato, um dos maiores problemas das declarações é que a audiência pode não saber como interpretá-las. As declarações, por si mesmas, podem meramente aumentar a desconfiança em relação ao palestrante e ao evento, revelando uma situação problemática sem prover os meios de resolvê-la ${ }^{13}$.

\section{CONSIDERAÇÕES FINAIS}

Apesar do número relativamente pequeno de sujeitos que participaram desta pesquisa, nossos resultados propiciam reflexões importantes para lidar com os conflitos de interesses em eventos de EMC.

Inicialmente, vale enfatizar que os participantes, em sua maioria, não desenvolveram uma competência para lidar com o tema durante o processo formal de educação médica. Além disso, é patente entre alguns palestrantes a preocupação com o despreparo da audiência para lidar com as informações contidas numa declaração de conflitos de interesses. Assim sendo, caberia às escolas médicas e aos serviços de residência médica investir esforços para melhorar o preparo dos futuros médicos e especialistas acerca dos conflitos em eventos de EMC.

Muitos dos sujeitos da pesquisa, em especial entre os palestrantes, demonstraram um justo anseio por regras mais claras e uniformes sobre o que deveria ser declarado. Mesmo a mais recente versão do Código de Ética Médica não especifica estas regras. O presente estudo oferece subsídios para uma enquete mais ampla, dirigida aos médicos brasileiros, com a finalidade de estabelecer de forma legítima e democrática o que deveria ser declarado e como fazê-lo. Acreditamos que entidades médicas, como o Conselho Federal de Medicina e suas regionais, bem como a Associação Médica Brasileira e as diferentes sociedades de especialidades, deveriam conduzir um trabalho neste sentido.

Ainda assim, não podemos fechar os olhos às situações de conflitos de interesses resultantes da exuberância financeira da indústria. A tentativa de evitar estes conflitos - ou pelo menos de criar regras para torná-los transparentes -deve ser encarada como um esforço para manter a confiança dos médicos nos cursos de educação continuada e a credibilidade social em nossa profissão. Nos EUA, por exemplo, esse esforço é dirigido à diminuição do custo dos eventos de EMC (por exemplo, escolhendo locais mais simples para o evento e evitando a promoção concomitante de atividades sociais), à proibição da participação da indústria (inclusive de médicos em situação de conflito de interesses) na comissão científica dos eventos e a uma cuidadosa verificação das declarações de conflitos de interesses ${ }^{20}$.

Estaremos fadados ao fracasso se lidarmos com um tema complexo como os conflitos de interesses por meio de noções simplistas, como uma luta maniqueísta dos justos contra os maus. Frente à complexidade do assunto, são indispensáveis o respeito à pluralidade de opiniões e o estabelecimento de procedimentos democráticos para a elaboração de normas legítimas, objetivas e exequíveis. Neste sentido, parece muito reduzida a visão que demoniza a indústria farmacêutica: são empresas num ramo extremamente competitivo que usam estratégias de marketing para alcançar seus objetivos de venda. E, apesar do poderio econômico dos "laboratórios", cabe aos médicos fazer valer seu poder - nada desprezível - de decisão: a venda de medicamentos passa por nossas prescrições; daí nossa obrigação de normatizar atividades que terão impacto final na saúde e no bolso dos pacientes.

\section{REFERÊNCIAS}

1. Abbasi K, Smith R. No more free lunches. Br Med J.2003; 326:1155-6.

2. Spithoff S. Industry involvement in continuing medical education. Can Fam Physician, 2014;60:694-6.

3. Steinbrook R. Financial Support of Continuing Medical Education. JAMA 2008;299(9):1060-2

4. Accreditation Council for Continuing Medical Education (ACCME). 2014 Annual Report. Acessado em: 16 Jan 2016. Disponível em: http://www.accme.org/news-publications / publications / annual-report-data / accme-annual-report-2014

5. Steinman MA, Landefeld CS, Baron RB. Industry Support of CME - Are We at the Tipping Point? N Engl J Med. 2012;366(12):1069-71

6. Herper M, Kang P. The World's Ten Best-Selling Drugs. 2006. Forbes Magazine. Acesso em: 10nov. 2015. Disponível em: http://www.forbes.com/home/sciencesandmedicine / 2006/03/21/pfizer-merck-amgen-cx_mh_ pk_0321topdrugs.html

7. Statista. Statistics and facts about the pharmaceutical industry worldwide. Acesso em: 13jan.2016. Disponível em http:/ / www.statista.com/topics /1764/global-pharmaceutical-industry/ 
8. World Health Organization. Pharmaceutical Industry. Acesso em: 13jan 2016. Disponível em: http:/ / www.who. int/trade/glossary/story073/en

9. INTERFARMA. Guia 2015 - Dados de Mercado. Acessado em 14 Jan 2016. Disponível em http:// www.interfarma.org.br/guia2015/site/guia/index. php?val=34\&titulo=Dados $\% 20 \mathrm{de} \% 20$ mercado

10. Brasil. Portal Brasil - Ministério da Saúde terá orçamento de R\$106 bilhões em 2014. Acesso em: 13jan.2016. Disponível em: http://www.brasil.gov.br/saude/2014/01/ saude-tera-orcamento-de-r-106-bilhoes-em-2014

11. Burton B, Rowell A. Unhealthy spin. Br Med J. 2003; 326:1205-7.

12. CREMESP. Bolsa de pesquisa. [homepage na internet]. Acesso: em 06 abr. 2015. Disponível em: http:/ / www.bioetica.org.br $/$ ?siteAcao=BolsaPesquisa\&tipo $=\mathrm{c} 09$

13. Thompson DF. Understanding Financial Conflicts of Interest. N Engl J Med, 1993;329(8):573-6.

14. Kassirer JP, Angell M.Financial Conflicts of Interest in Biomedical Research. N Engl J Med 1993;329(8):570-1.

15. Lemmens T, Singer PA. Bioethics for clinicians: 17. Conflict of interest in research, education and patient care. Can Med Assoc J,1998;159:960-5.

16. Leite F. Médicos debatem relação com empresa. O Estado de São Paulo, 26 de Outubro de 2008.

17. Conselho Federal de Medicina. Resolução no $1.595 / 2000$. [homepage na internet]. Acesso em: 03 abr. 2015. Disponível em: http://www.portalmedico.org.br/resolucoes/ cfm/2000/1595_2000.htm

18. Posicionamento do CFM, da AMB, da SBC e da INTERFARMA em defesa das boas práticas no relacionamento entre classe médica e a indústria farmacêutica. 2012. Acesso wm: 03 abr. 2015.Disponível em http://portal.cfm.org. $\mathrm{br} /$ images / stories / pdf/protocolo $\% 20 \mathrm{cfm} \% 20$ interfarma\%20final.pdf

19. Haines EI, Olver IN.Are self-regulation and declaration of conflict of interest still the benchmark for relationships between physicians and industry?Med J Aust, 2008; 189 (5): 263-6.
20. Schofferman J. The Medical-Industrial Complex, ProfessionalMedical Associations, and ContinuingMedical Education. Pain Med 2011;12:1713-9

\section{CONTRIBUIÇÃO DOS AUTORES}

José Domingos Neto participou de forma suficiente na concepção e desenho do estudo, da coleta de dados por meio de entrevista estruturada aos sujeitos da pesquisa e da análise e interpretação dos dados assim como da redação do texto, para assumir a autoria e a responsabilidade pública pelo conteúdo do artigo.

Aluísio Marçal de Barros Serodio participou de forma suficiente na concepção e desenho do estudo e da análise e interpretação dos dados assim como da redação do texto, para assumir a autoria e a responsabilidade pública pelo conteúdo do artigo.

João Alexandre Hool Bajerl participou de forma suficiente na concepção e desenho do estudo, da coleta de dados por meio de entrevista estruturada aos sujeitos da pesquisa e da análise e interpretação dos dados assim como da redação do texto, para assumir a autoria e a responsabilidade pública pelo conteúdo do artigo.

\section{CONFLITO DE INTERESSES}

Não há qualquer tipo de conflito de interesses relacionado a qualquer um dos autores citados neste artigo.

\section{ENDEREÇO PARA CORRESPONDÊNCIA}

José Domingos Neto

New Classic Business Center

Rua Afonso Celso, n. 552, Segundo andar, Conjunto 23, Vila

Clementino

CEP 04119-000 São Paulo, SP, Brasil

Email: jdneto73@gmail.com 